\title{
Horizontal refraction of propagating sound due to seafloor scours over a range-dependent layered bottom on the New Jersey shelf
}

\author{
Megan S. Ballard ${ }^{\text {a) }}$ \\ Applied Research Laboratories, University of Texas at Austin, 10000 Burnet Road, Austin, Texas 78758 \\ Ying-Tsong Lin and James F. Lynch \\ Applied Ocean Physics and Engineering Department, Woods Hole Oceanographic Institution, Woods Hole, \\ Massachusetts 02543
}

(Received 1 September 2011; revised 17 January 2012; accepted 24 January 2012)

\begin{abstract}
Three-dimensional propagation effects of low frequency sound from 100 to $400 \mathrm{~Hz}$ caused by seafloor topography and range-dependent bottom structure over a $20 \mathrm{~km}$ range along the New Jersey shelf are investigated using a hybrid modeling approach. Normal modes are used in the vertical dimension, and a parabolic-equation approximate model is applied to solve the horizontal refraction equation. Examination of modal amplitudes demonstrates the effect of environmental range dependence on modes trapped in the water column, modes interacting with the bottom, and modes trapped in the bottom. Using normal mode ray tracing, topographic features responsible for threedimensional effects of horizontal refraction and focusing are identified. These effects are observed in the measurements from the Shallow Water 2006 experiment. Specifically, signals from a pair of fixed sources recorded on a horizontal line array sitting on the seafloor show an intensification caused by horizontal focusing due to the seabed topography of $4 \mathrm{~dB}$ along the array.
\end{abstract}

(C) 2012 Acoustical Society of America. [http://dx.doi.org/10.1121/1.3687446]

PACS number(s): 43.30.Bp, 43.20.El, 43.30.Re [AIT]

Pages: $2587-2598$

\section{INTRODUCTION}

In typical applications of modeling underwater sound propagation, three-dimensional (3-D) effects are assumed to be relatively weak and two-dimensional (2-D) models are applied on a vertical plane to predict acoustic signals. However, this assumption breaks down for many shallow-water environments. Evidence of horizontal refraction has been documented in the context of nonlinear internal waves ${ }^{1-3}$ and sloping bathymetry. ${ }^{4-7}$ In this work, 3-D effects caused by seafloor scours and sub-bottom structure on the New Jersey shelf are considered. Acoustic data collected during the Shallow Water 2006 experiment $^{8}$ (SW06) are examined and evidence of horizontal focusing is observed in the recorded data.

The SW06 experiment took place on the New Jersey shelf area of the Mid-Atlantic Bight in the summer of 2006. Acoustic propagation from two closely located sources to a fixed array station (the Shark array), located approximately $20 \mathrm{~km}$ away from the sources along the shelf, is modeled using 3-D adiabatic normal mode theory. The model makes use of high resolution environmental data for the bathymetry and sub-bottom structure. The effects of horizontal refraction and focusing caused by seafloor scours can be seen in the modeled and measured data. By including the 3-D sub-bottom structure in the model, the predicted acoustic field at the array location agree well with the experimental data.

This paper is organized as follows: in Sec. II, the 3-D propagation model applied in this work is presented. The

\footnotetext{
a) Author to whom correspondence should be addressed. Electronic mail: meganb@arlut.utexas.edu.
}

detailed environmental data of the New Jersey shelf are described in Sec. III. Modeling results are presented in Sec. IV. Observations of horizontal focusing from the SW06 data are compared to model predictions in Sec. V. Conclusions are contained in Sec. VI.

\section{THEORY}

In recent decades, a number of propagation codes suitable for calculating transmission loss (TL) in environments for which 3-D effects are important have been developed. ${ }^{9-16}$ In this work, a normal mode approach is applied. The field decomposition into modal amplitudes provides insight into the effects of environmental inhomogeneities on the acoustic field.

The inhomogeneous Helmholtz equation for pressure $P(x, y, z)$ due to a point continuous wave source of amplitude $S(\omega)$ located at $\left(x_{0}, y_{0}, z_{0}\right)$ is

$$
\begin{aligned}
& \rho(x, y, z) \nabla \cdot\left[\frac{1}{\rho(x, y, z)} \nabla P(x, y, z)\right]+k^{2}(x, y, z) P(x, y, z) \\
& =-4 \pi S(\omega) \delta\left(x-x_{0}\right) \delta\left(y-y_{0}\right) \delta\left(z-z_{0}\right)
\end{aligned}
$$

where $k=\omega / c(x, y, z), \omega=2 \pi f, f$ is the acoustic frequency, and $c(x, y, z)$ is sound speed.

The solution for pressure can be found from normal mode theory

$$
P(x, y, z)=\sum_{n} R_{n}(x, y) \phi_{n}(z ; x, y),
$$


where modal amplitudes $R_{n}(x, y)$ satisfy $^{17}$

$$
\begin{aligned}
& \frac{\partial^{2} R_{m}}{\partial x^{2}}+\frac{\partial^{2} R_{m}}{\partial y^{2}}+k_{m}^{2}(x, y) R_{m} \\
& =\sum_{n}\left[\left(A_{m n}+\alpha_{m n}\right) R_{n}+\left(\vec{B}_{m n}+\vec{\beta}_{m n}\right) \cdot \nabla_{t} R_{n}\right] \\
& \quad-4 \pi S(\omega) \delta\left(x-x_{0}\right) \delta\left(y-y_{0}\right) \frac{\phi_{m}\left(x_{0}, y_{0}, z_{0}\right)}{\rho\left(z_{0}\right)}
\end{aligned}
$$

and the modal eigenfunctions $\phi_{n}(z ; x, y)$ satisfy

$$
\begin{aligned}
& \rho(x, y, z) \frac{\partial}{\partial z}\left[\frac{1}{\rho(x, y, z)} \frac{\partial \phi_{n}(z ; x, y)}{\partial z}\right] \\
& \quad+\left[k^{2}(x, y, z)-k_{n}^{2}(x, y)\right] \phi_{n}(z ; x, y)=0,
\end{aligned}
$$

with boundary conditions defined by the plane wave reflection coefficient at the sea surface and above the lower halfspace. $^{18}$

In Eq. (3), $\nabla_{t}$ is the transverse operator defined by

$$
\nabla_{t}=\hat{x} \frac{\partial}{\partial x}+\hat{y} \frac{\partial}{\partial y}
$$

and $A_{m n}$ and $\vec{B}_{m n}$ are given by

$$
\begin{aligned}
& A_{m n}(x, y)=\int_{0}^{\infty} \frac{1}{\rho(x, y, z)} \phi_{m}(z ; x, y) \nabla_{t}^{2} \phi_{n}(z ; x, y) d z \\
& \vec{B}_{m n}(x, y)=2 \int_{0}^{\infty} \frac{1}{\rho(x, y, z)} \phi_{m}(z ; x, y) \nabla_{t} \phi_{n}(z ; x, y) d z,
\end{aligned}
$$

and $\alpha_{m n}$ and $\vec{\beta}_{m n}$ are the interface coupling matrices which account for non-horizontal interfaces. ${ }^{19}$

In the analysis presented here, the mode-coupling is assumed to be negligible; hence, the coupling coefficients $A_{m n}$ and $\vec{B}_{m n}$ of Eq. (3) are set to zero. The accuracy of applying the adiabatic approximation in the 3-D propagation model used in this paper is assessed in the Appendix. Neglecting the coupling coefficients leads to the horizontal refraction equation:

$$
\begin{aligned}
\frac{\partial^{2} R_{m}}{\partial x^{2}}+\frac{\partial^{2} R_{m}}{\partial y^{2}}+k_{m}^{2}(x, y) R_{m}= & -4 \pi S(\omega) \delta\left(x-x_{0}\right) \\
& \times \delta\left(y-y_{0}\right) \frac{\phi_{m}\left(x, y, z_{0}\right)}{\rho\left(z_{0}\right)},
\end{aligned}
$$

where $k_{m}(x, y)$ is the complex horizontal wavenumber of the $m$ th mode. Eq. (6) must be solved for each mode with the horizontal refraction determined by the modal phase speed $c_{p h_{m}}(x, y)=\omega / \operatorname{Re}\left\{k_{m}(x, y)\right\}$ and modal attenuation $\alpha_{m}(x, y)$ $=\operatorname{Im}\left\{k_{m}(x, y)\right\}$. Such a two-dimensional Helmholtz equation can be solved using standard techniques, i.e., normal modes, parabolic equation, or ray theory.

In this work, $\mathrm{ORCA}^{18}$ is used to calculate the modal eigenvalues and eigenfunctions. ORCA is chosen for this task as it solves for modes in the continuous spectrum which provides a consistent treatment for modes which propagate at the source and receiver locations but are past cut-off elsewhere in the horizontal plane. The horizontal refraction equation is solved using a parabolic-equation approximate mode $^{20}$ with artificial absorbing layers placed on the sides of the model domain.

\section{ENVIRONMENTAL DESCRIPTION}

The seabed of the New Jersey shelf is characterized by seafloor scouring and high spatial variability of sediment properties. The area surrounding the axis of the SW06 experiment was extensively surveyed in 2001-2002 using Compressed High Intensity Radar Pulse (CHIRP) sonar. ${ }^{21} \mathrm{~A}$ grid of closely spaced tracks provided the basis for a stratigraphic model for this part of the shelf. Additional measurements taken during the SW06 experiment augment the earlier work with longer, more widely spaced tracks covering a larger area. ${ }^{22}$ These data, shown in Fig. 1, were used to construct the environmental model used in the 3-D sound propagation calculation. The depth of the seafloor, Fig. 1(a), shows scouring in the along-shelf direction. The "R" reflector, Fig. 1(b), varies with depth on the shelf, and in much of the area considered in this study, it is covered with approximately $20 \mathrm{~m}$ of sediment known as the outer shelf wedge. ${ }^{23,24}$ The erose boundary, Fig. 1(c), located between the seafloor and "R" reflector, was created by a major erosional episode of indeterminate origin. ${ }^{23,25}$ The white areas on Figs. 1(b) and 1(c) represent regions where layers are truncated. For example, the erose boundary rises to meet the seafloor in the northwest and dips to meet the " $R$ " reflector to the southeast.

The locations of the Miami Sound Machine source (MSM), the Naval Research Lab $300 \mathrm{~Hz}$ source (NRL), and the Shark vertical line array (VLA) are also shown in Fig. 1 . The MSM source is located at $39^{\circ} 10.8708^{\prime} \mathrm{N}, 72^{\circ}$ $57.0387^{\prime} \mathrm{W}$. The NRL source is located $686 \mathrm{~m}$ to the (a) Topography

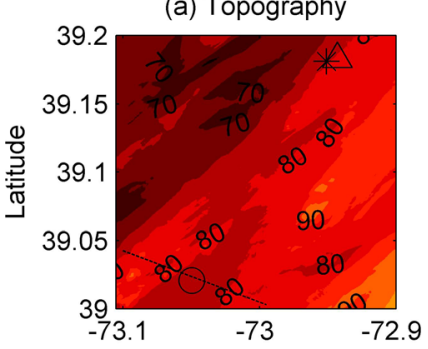

(c) Erose Boundary

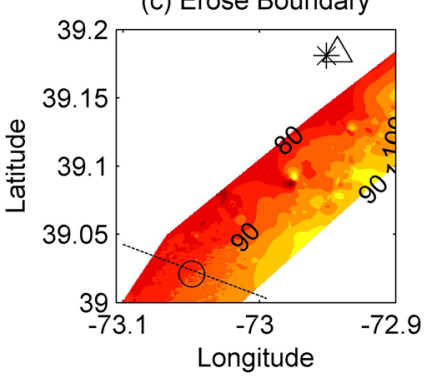

(b) R-Reflector

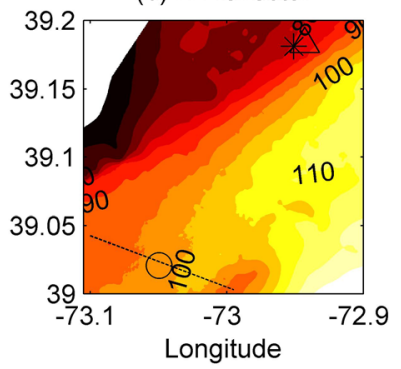

Longitude
FIG. 1. (Color online) Depth of the (a) seafloor, (b) "R" reflector, and (c) erose boundary. The dashed reference line to the SW marks the location used to plot across-shelf TL in Fig. 9. 
northeast at $39^{\circ} 10.9574^{\prime} \mathrm{N}, 72^{\circ} 56.5750^{\prime} \mathrm{W}$. The Shark VLA is located approximately $20 \mathrm{~km}$ to the southwest of the sources at $39^{\circ} 01.2627^{\prime} \mathrm{N}, 73^{\circ} 02.9887^{\prime} \mathrm{W}$.

A 3-D model of sediment sound speed on the New Jersey shelf was constructed using a combination of inversion results $^{22}$ and CHIRP seismic data. ${ }^{21,22}$ Based on this information, a model was specified to be composed of layers having constant sound speeds. Spatial variability of the model was attributed solely to changes in the layer depths and thicknesses as determined by the CHIRP data shown in Fig. 1. The sound speed values obtained by geoacoustic inversions were determined using acoustic data from ship tracks located within $7 \mathrm{~km}$ of the Shark array and these results were extrapolated over a broader area using the CHIRP seismic data. The validity of extending the geophysical model in this way was confirmed by accurately predicting travel time measurements from an acoustic pulse originating $15 \mathrm{~km}$ northeast of the Shark array ${ }^{22}$ and by examining horizontal wave number data recorded on another hydrophone array located at $73^{\circ} 7.842^{\prime}$ $\mathrm{W}, 39^{\circ} 3.618^{\prime} \mathrm{N}$. A slice through the 3-D sediment model oriented in the across-shelf direction and intersecting Shark array is shown in Fig. 2. This plot corresponds to the location marked by the dashed lines in Fig. 1. The truncation of the erose boundary with the seafloor is clearly visible in Fig. 2 . The initial deposition of the outer shelf wedge directly above the " $R$ " reflector consists of finely laminate dipping layers of alternating sandy clay and clay. ${ }^{26}$ In the 3 -D geoacoustic seabed model, this layer is characterized by a sound speed of $1585 \mathrm{~m} / \mathrm{s}$. Cores into the shallower sediment above the erose boundary primarily sampled clay, with occasional sand lenses. $^{22}$ This layer of sediment is modeled with a sound speed of $1670 \mathrm{~m} / \mathrm{s}$. Because the 3-D sediment model only provides estimates for sound speed, constant density and attenuation profiles of $1.5 \mathrm{~g} / \mathrm{cm}^{3}$ and $0.1 \mathrm{~dB} / \lambda$ were assumed. The lack of further information on the density and acoustic attenuation in the sediment affects the accuracy of the calculated sound intensity. Nevertheless, with good estimates of the bottom sound speed, the real sound refraction can be captured.

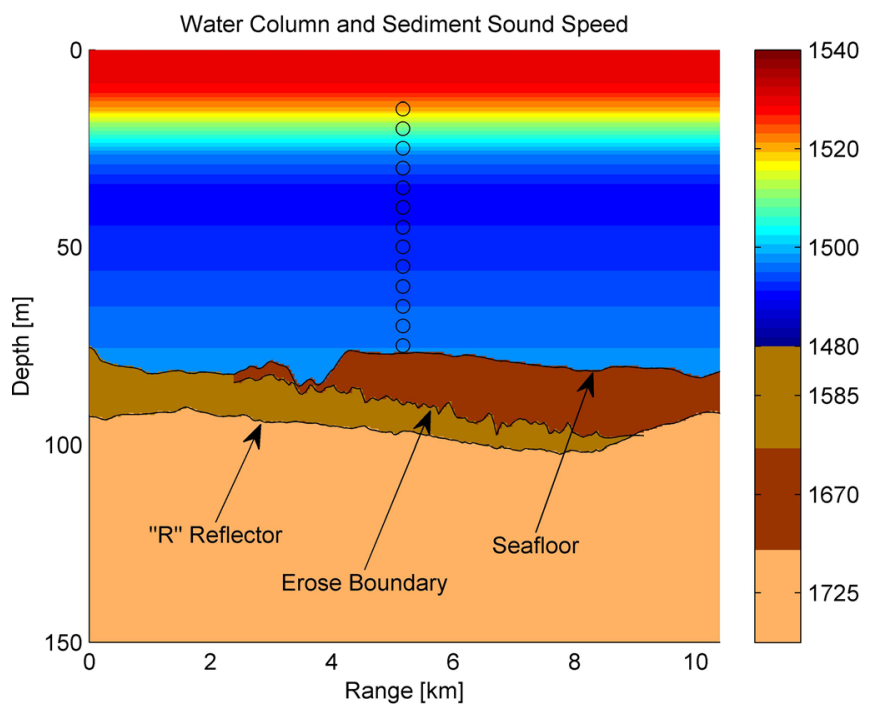

FIG. 2. (Color online) Water column and sediment sound speed across the shelf in-line with the Shark VLA; the open circles mark the location of the Shark VLA.
The water-column sound-speed profile is also known to have significant effects on acoustic propagation. ${ }^{27-30}$ The water column on the New Jersey shelf experiences seasonal variability; it is highly stratified during the summer and well-mixed during the winter. ${ }^{31} \mathrm{~A}$ sound-speed profile representative of the summer, shown in Fig. 2, was used in this modeling effort. The profile is taken from time-averaged measurements recorded at the location of the Shark array, which was equipped with temperature sensors spanning the water column and a single pressure sensor. Salinity was spatially interpolated from an environmental mooring, approximately $1.5 \mathrm{~km}$ to the west-northwest of the Shark VLA at $39^{\circ} 07.175^{\prime} \mathrm{N}, 73^{\circ} 16.640^{\prime} \mathrm{W}$, by fitting the temperature data to the temperature versus salinity curve (T-S curve). ${ }^{32}$ Although range-dependent water-column sound-speed profiles and rough sea surface conditions are known to cause significant 3-D effects, ${ }^{1-3,33-36}$ a single, averaged profile and flat sea surface are used in this work so that the modeled effects are due to variability of the topography and subbottom structure alone with a baseline vertical refraction due to the mean sound speed gradient.

\section{MODELING RESULTS}

The 3-D adiabatic normal mode technique described in Sec. II was applied to model acoustic propagation over the shelf. The solution was calculated for four cases characterized by various levels of environmental variability. The cases were chosen to isolate the effects of range-dependent topography from bottom structure as well as to understand their interaction. Case 1 is the "control" case and consists of smoothed seafloor topography over a range-independent halfspace with sound speed of $1670 \mathrm{~m} / \mathrm{s}$, density of $1.5 \mathrm{~g} / \mathrm{cm}^{3}$, and attenuation of $0.1 \mathrm{~dB} / \lambda$. The smoothed topography was obtained by filtering the measured topography [shown in Fig. 1(a)] using a $3 \mathrm{~km} \times 3 \mathrm{~km}$ moving average. Case 2 highlights the effects the range-dependent seabed. For this case, the layer thicknesses described by the CHIRP seismic data are preserved, but the smoothed seafloor topography is used. Case 3 examines the 3-D effects caused by topography by using the measured seafloor depth with the bottom being the same rangeindependent halfspace considered in Case 1. Case 4 investigates the combined effects of seafloor topography and the range-dependent bottom. For this instance, all the rangedependent features described by Fig. 1 are included. The four cases are summarized in Table I.

In the rest of this section, numerical modeling results from each of the four variations on the environment are described. First, propagation for individual modes at a frequency of $200 \mathrm{~Hz}$ is examined and specific environmental features responsible for the observed 3-D effects are

TABLE I. Environment description.

\begin{tabular}{lcl}
\hline \hline Case & Topography & \multicolumn{1}{c}{ Seabed } \\
\hline 1 & Smoothed & Halfspace \\
2 & Smoothed & Layered \\
3 & Measured & Halfspace \\
4 & Measured & Layered \\
\hline \hline
\end{tabular}


identified. Then the total field is considered by examining TL over the shelf at a range of approximately $20 \mathrm{~km}$ from the source for several frequencies. This analysis is carried out for sound propagating from the location of the MSM source.

\section{A. Modal amplitude}

The relative effects of seafloor topography and bottom structure on the acoustic modes depend significantly on vertical mode angle. Low-order modes, which are associated with shallower propagation angles, are contained almost exclusively in the water column and are not significantly affected by the range-dependence of the topography or seabed. On the other hand, high-order modes, which propagate at higher angles with respect to the horizontal, interact more with the bottom and can experience considerable horizontal refraction. An understanding of these effects is gained by examining the modal amplitude of selected modes at frequency of $200 \mathrm{~Hz}$. Modal amplitude is calculated according to Eq. (6), but to allow for easy comparison between the modes, modal amplitude $R_{m}$ is normalized by the eigenfunction at the source location $\phi_{m}\left(x_{0}, y_{0}, z_{0}\right)$ so that modal amplitude at the source location is unity.

The modal amplitude of mode one at $200 \mathrm{~Hz}$ is plotted for each of the four cases in Fig. 3. Modal amplitude appears identical for all four cases and the difference in TL between Case 1 and Cases 2, 3, and 4 across the shelf in-line with the dashed line in Fig. 1 is less than $0.25 \mathrm{~dB}$. This result is typical of non-bottom interacting modes and the small effect of horizontal refraction is expected as modal phase speed varies by less than $1 \mathrm{~m} / \mathrm{s}$ across the study area. Low-order modes are known to be more sensitive to water-column variability than range-dependent bottom properties. ${ }^{29,37}$

The amplitude of mode seven at $200 \mathrm{~Hz}$, a bottominteracting mode, is shown in Fig. 4. Examination of Fig. 4(a) shows a departure from cylindrical spreading as the smoothed bathymetry causes refraction down the shelf. Comparing Cases 1 and 2, it is observed that inclusion of the layered bottom results in increased attenuation which is most evident to the southwest where the slower sediment above the " $R$ " reflector is exposed at the seafloor. The increased modal attenuation can be understood from an examination of the depth-dependent eigenfunctions: for Case 1, the depthdependent eigenfunctions decay exponentially in the seabed; for Case 2, the increased complexity of the seabed results in mode functions which penetrate more deeply into the sediment. Case 3, for which the range dependence is caused by changes in topography alone, shows significant horizontal refraction. Focused beams are formed by the scoured features of the seafloor. The effects of both the topography and the range-dependent bottom are observed in Case 4 in the form of horizontal focusing and increased attenuation.

Comparison across the four cases of modal amplitude for mode seven at $200 \mathrm{~Hz}$ (Fig. 4) demonstrates that the topography has the dominant effect on horizontal refraction. This is an expected result as the sound speed and density contrast between the water column and seabed is greater than that of the sub-bottom layers. To identify the specific topographic features responsible for the horizontal refraction observed in the mode amplitude levels, a normal mode ray trace was performed. The ray trace was calculated for Cases (a) Case: 1

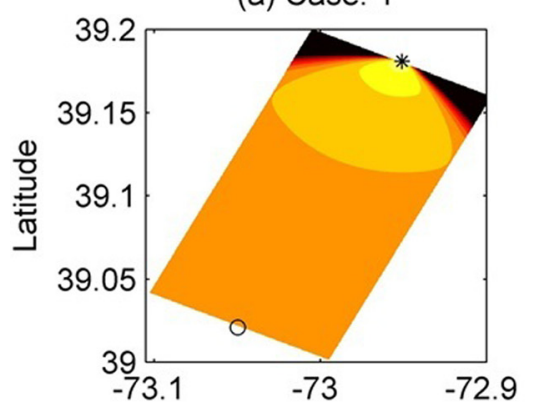

(c) Case: 3

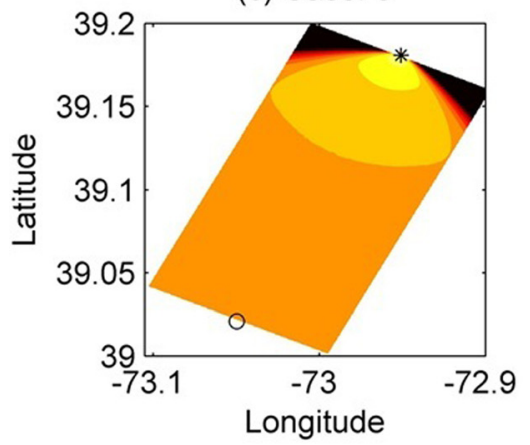

(b) Case: 2

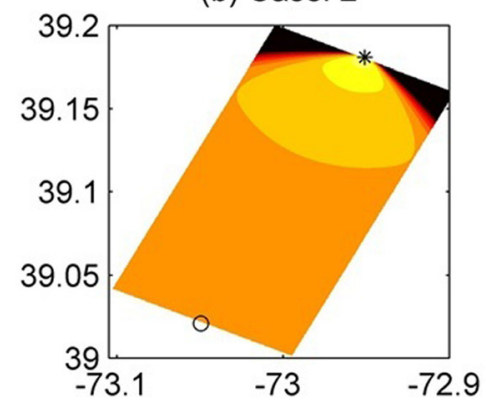

(d) Case: 4

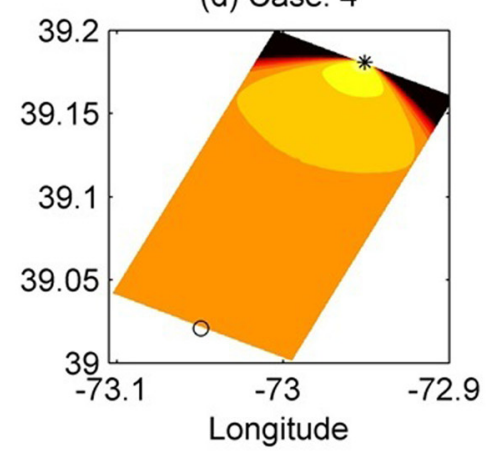

FIG. 3. (Color online) Modal amplitude for mode one due to a $200 \mathrm{~Hz}$ source for each of the four cases; the star represents the location of the MSM source and the circle is the location of the Shark VLA.

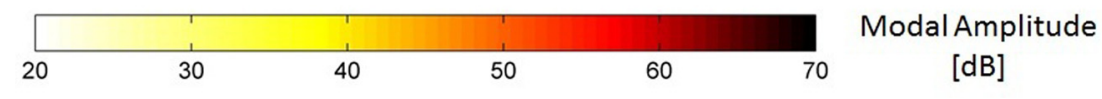


(a) Case: 1

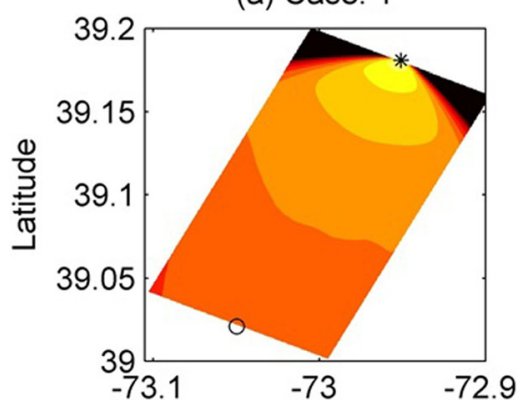

(c) Case: 3

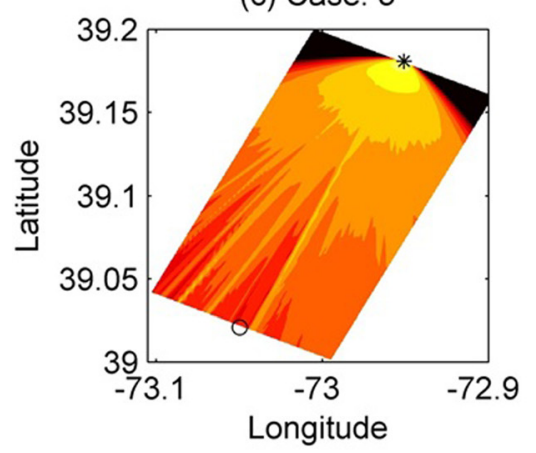

(b) Case: 2

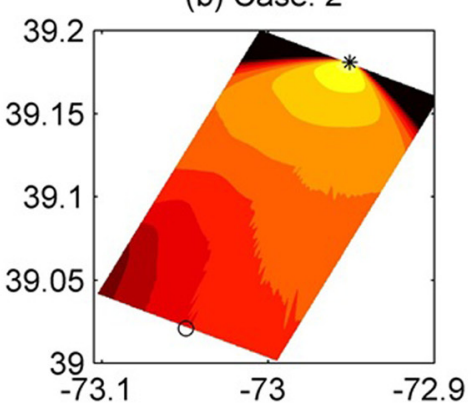

(d) Case: 4

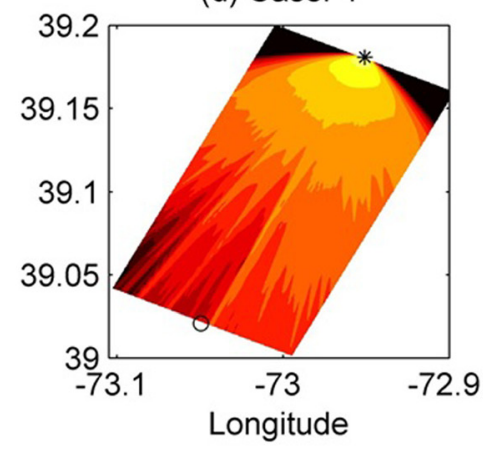

FIG. 4. (Color online) Modal amplitude for mode seven due to a $200 \mathrm{~Hz}$ source for each of the four cases; the star represents the location of the MSM source and the circle is the location of the Shark VLA.

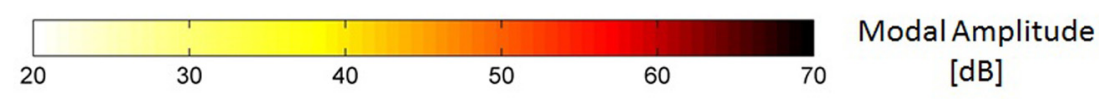

1 and 3 [Figs. 4(a) and 4(c)] so that the observed effects are due to range-dependent topography alone. For each of these cases, 81 rays were traced spanning an angular sector between $50^{\circ}$ and $130^{\circ}$, with $0^{\circ}$ orientated up the shelf perpendicular to a reference line drawn between the MSM and the Shark VLA. These ray traces are overlaid on the smoothed and measured bathymetry in Fig. 5. Comparison of Figs. 5(b) and 4(c) shows rays are concentrated in a regions of increased modal amplitude. The smoothed topography results in less refraction as indicated by the straighter rays and the lack of caustics.

For the measured and smoothed topography, the effect of horizontal refraction on the individual rays was examined by measuring their curvature. Ray curvature was quantified by comparing the length of the refracted ray to a straight (non-refracted) ray. The percent difference in length between the straight and refracted rays is plotted in Fig. 6(a). As expected, the ray curvature is greater for the measured topography. For both environments, the ray with the greatest curvature corresponds to a ray launch angle of $73^{\circ}$. In Fig. 5, this ray is highlighted by the thick line. The dominant feature affecting this ray is the general upward slope of the shelf toward the northwest. This feature is further examined in Fig. 6(b) which shows water depth along the $39^{\circ} 8.040^{\prime} \mathrm{N}$ latitude. Pointed out as the "broad feature," the upward slope of the shelf can be observed in both the smoothed and measured topography, causing a change in the average water depth of $5 \mathrm{~m}$. Although this relatively small change in depth associated with a rather weak gradient in modal phase speed, it occurs over a wide area and results in significant ray curvature because the sound is continuously interacting with the bottom over a long range. The steeper slope of the measured topography causes a larger gradient in modal phase speed which results in the greater curvature of the $73^{\circ}$ ray.

A second observation from Fig. 6(a) is the local maximum in ray curvature corresponding to an launch angle of $87^{\circ}$ for the case of the measured topography. This ray passes over a deeper region localized at $39^{\circ} 8.040^{\prime} \mathrm{N}, 72^{\circ} 58.80^{\prime} \mathrm{W}$. This feature is pointed out in Fig. 6(b) as a "localized feature" and can only be observed in the measured bathymetry data. Because of its size, it is filtered out of the smoothed bathymetry. In this location, the water depth is approximately $7 \mathrm{~m}$ deeper than the average water depth in the immediate surrounding area. This change in water depth is responsible for a decrease in modal phase speed of $13 \mathrm{~m} / \mathrm{s}$. Although this feature represents a relatively small change in water depth, it occurs over a short range and results in a large gradient in modal phase speed. Several rays pass over this feature causing them to bend to the south, resulting in caustics which begin to form at a range of $14 \mathrm{~km}$ and continuing through a range of $20 \mathrm{~km}$.

The next thing we examine is modes which are resonant in the low speed layer of the seabed. Resonant modes are characterized by mode functions which are strongly amplified within a layer. ${ }^{38-40}$ This effect is illustrated by mode shapes calculated at $200 \mathrm{~Hz}$ for a single point in the $x-y$ plane (corresponding to $73.02 \mathrm{~W}, 39.01 \mathrm{~N}$-the approximate location of the Shark VLA) shown by the solid lines in Fig. 7. The dashed lines in the figure indicate the depth of the seafloor, erose boundary, and " $\mathrm{R}$ " reflector. Mode nine is identified as a resonant mode from its high amplitude in the low-speed layer. 

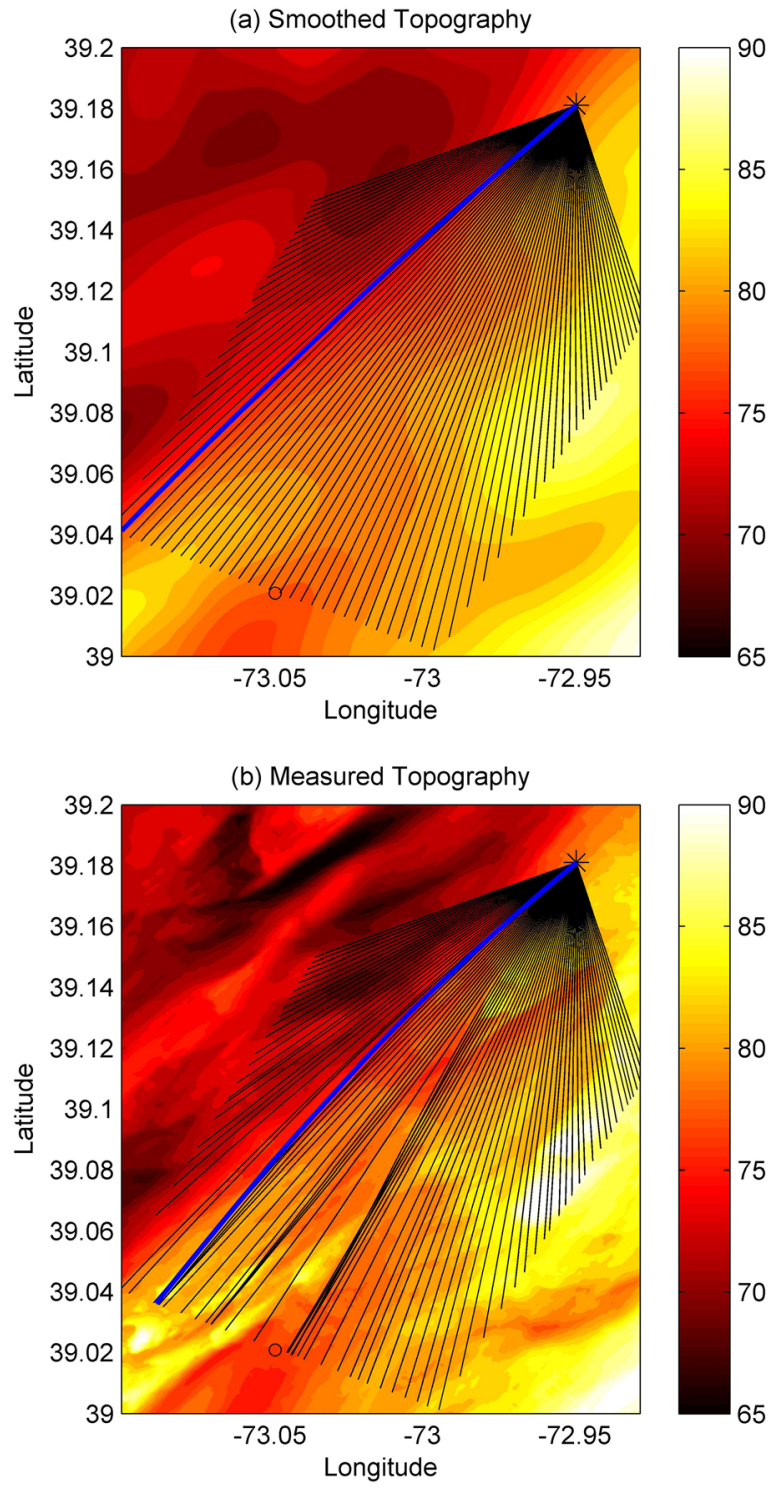

FIG. 5. (Color online) Ray trace for mode seven due over (a) smoothed and (b) measured topography; the star represents the location of the MSM and the circle is the location of the receiver array. The ray with the most curvature is highlighted by the thick line.

The modal amplitude for mode nine at $200 \mathrm{~Hz}$ is shown in Fig. 8. Comparison of modal amplitudes for Cases 1 and 2 shows dramatically different propagation regimes. For the case of the range-dependent layered bottom which contains the low speed layer, mode nine is severely attenuated to the south and east of the source. This occurs because most of its energy is trapped within the low speed layer of the seabed and suffers from bottom medium attenuation. Very low modal amplitude is also observed for Case 1 west of the source. This occurs because mode nine goes through mode cut-off as the water depth shallows in the shoreward direction. In this region, mode nine is a leaky mode and has high modal attenuation associated with it. These resonant and leaky mode effects are also observed for Cases 3 and 4. However, for these cases, in regions where the field is not attenuated, the measured topography is responsible for horizontal refraction effects similar to those observed for mode seven. (a) Percent Change in Ray Length

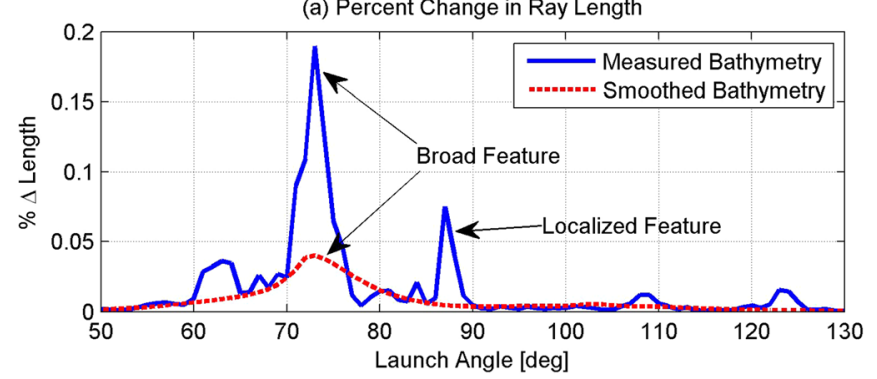

(b) Water Depth at Latitude $=39^{\circ} 8.040^{\prime} \mathrm{N}$

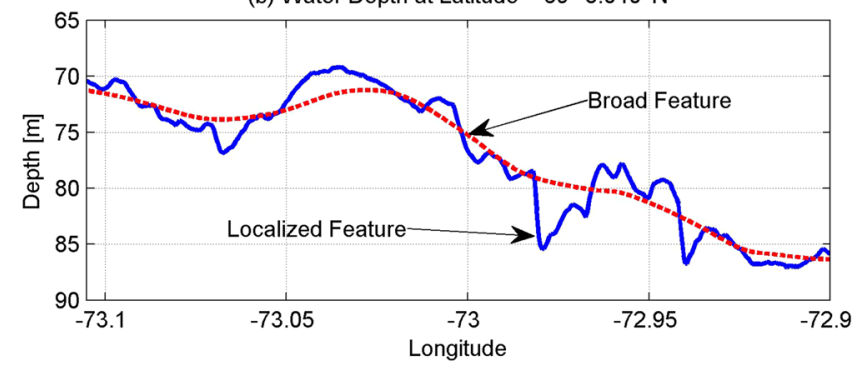

FIG. 6. (Color online) (a) Ray curvature versus ray launch angle, and (b) measured and smoothed topography along latitude of $39^{\circ} 8.040^{\prime} \mathrm{N}$.

The motivation for examining 3-D effects for a resonant mode is that the eigenvalues of higher order modes can be more sensitive to seabed properties than changes in bathymetry. ${ }^{41}$ Although significant horizontal refraction effects are not observed in Fig. 8(b) for Case 2 (smoothed bathymetry and layered bottom) due to high modal attenuation, a normal mode ray trace confirms that the modal phase speed gradients caused by the sub-bottom structure are significant and result in the same type of horizontal focusing observed in Fig. 5. In particular, the dip in the depth of the erose boundary located at $39.01 \mathrm{~N}, 72.98 \mathrm{~W}$ [see Fig. 1(c)] was responsible for a change in modal phase speed of $42 \mathrm{~m} / \mathrm{s}$. This feature causes the interacting ray to bend $0.14 \%$ longer than the corresponding straight ray path. This magnitude of ray

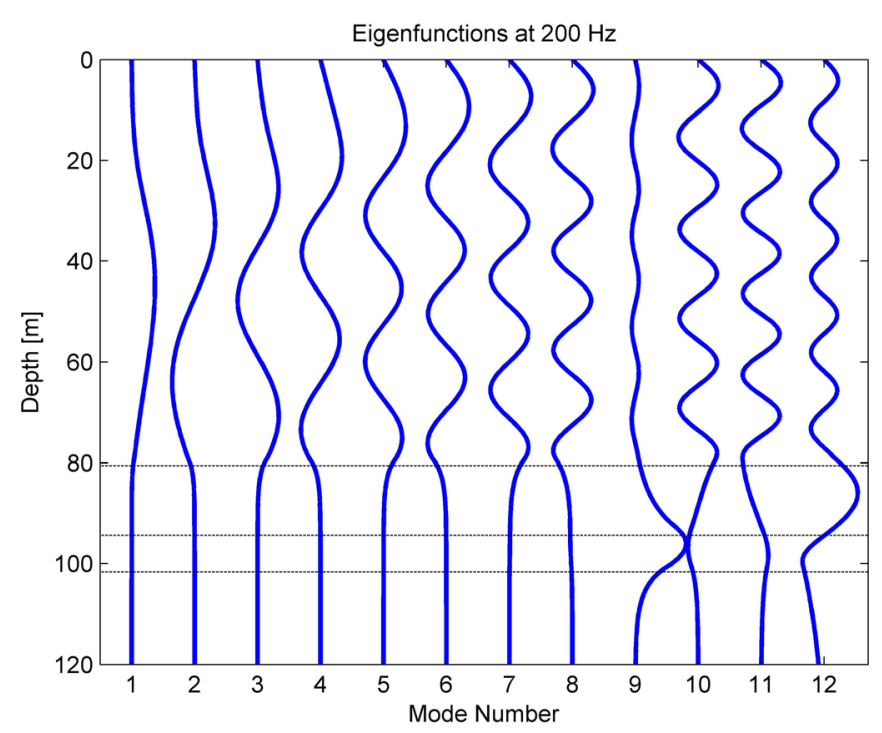

FIG. 7. (Color online) Modes shapes calculated for a frequency of $200 \mathrm{~Hz}$. The dashed lines represent the depth of the seabed, the erose boundary, and "R" reflector. 
(a) Case: 1

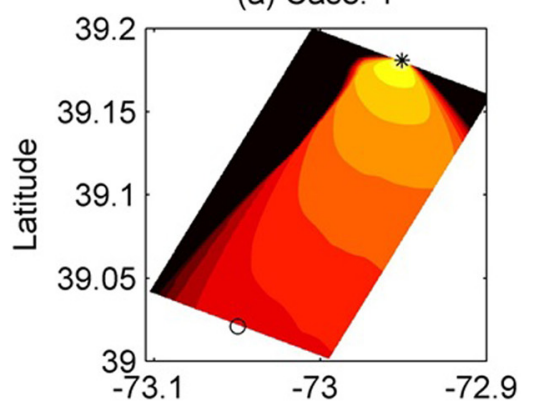

(c) Case: 3

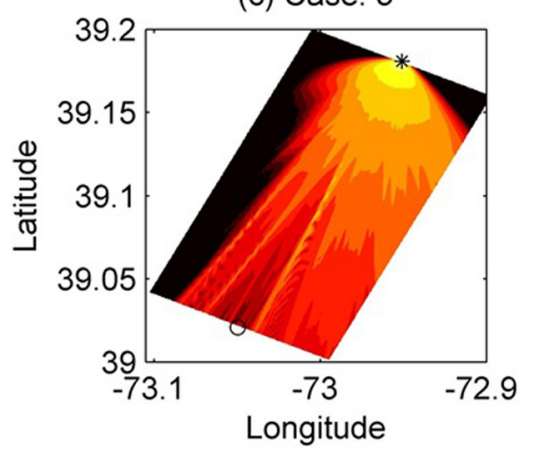

(b) Case: 2

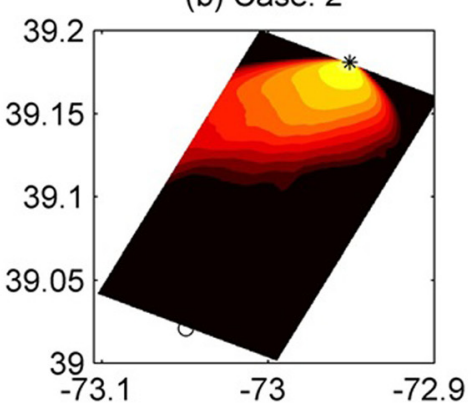

(d) Case: 4

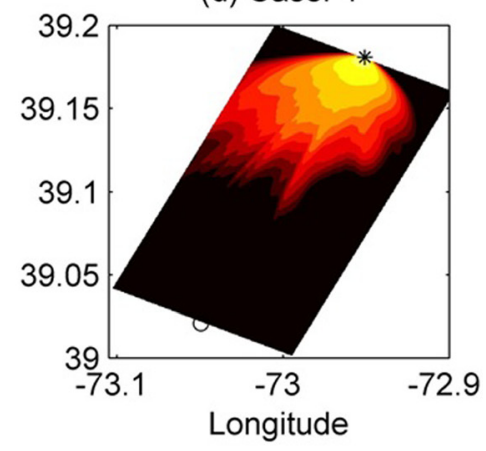

FIG. 8. (Color online) Modal amplitude for mode nine due to a $200 \mathrm{~Hz}$ source for each of the four cases; the star represents the location of the MSM source and the circle is the location of the Shark VLA.

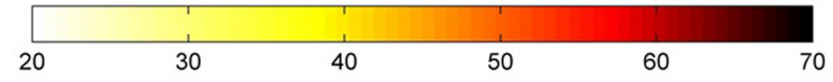

curvature is on the order of the "localized feature" effect examined for the seafloor topography as shown in Fig. 6(a).

\section{B. Total field}

The acoustic field was calculated at several frequencies: $50,100,200,300$, and $400 \mathrm{~Hz}$. The same four variations on the shallow-water waveguide addressed above (see Table I) are also considered here. For all cases, the source and receiver depths are 50 and $20 \mathrm{~m}$, respectively. TL across the shelf in-line with the dashed line shown in Fig. 1 are plotted in Fig. 9. The incoherent mode sum is considered in order to separate the effects of horizontal refraction from the modal interference pattern. In addition, the modeled incoherent mode sum from a single frequency can, in general, represent the intensity of a narrowband pulse whose modal arrivals are separated in time without interfering with each other, especially when the magnitude of the channel response is uniform across the frequency band.

For all five frequencies, there are several consistent features in the results. The range-dependent, layered bottom (Cases 2 and 4) is characterized by higher loss than the halfspace bottom (Cases 1 and 3 ). This phenomenon was described for the study of individual mode amplitudes in Sec. IV B, and is caused by increased modal penetration into the seabed. Additionally, for all frequencies, comparison of Cases 1 and 2 shows that including the range-dependent layered bottom results in greater loss to the west. For most bottom interacting modes, sound is refracted into this region which is characterized by lower surficial sound speed and, therefore, lower modal phase speed. However, the weak horizontal refraction effect of the sub-bottom is masked by
Modal Amplitude $[\mathrm{dB}]$ increased attenuation which results from deeper modal penetration into the seabed. Another consistent result is that range-dependent topography is responsible for most of the horizontal refraction; this is shown clearly in the plots as Cases 3 and 4 show significantly more across-shelf variability than Cases 1 and 2. Finally, although the main difference between Cases 3 and 4 appears to be the overall shift in TL, some differences in the peaks caused by horizontal refraction can be observed. Including the range-dependent sub-bottom shifts the locations of the peaks and adjusts their relative amplitudes.

The results displayed in Fig. 9 are further examined in Table II which shows the standard deviation of the difference in TL between Cases 1 and 3 (range-independent halfspace bottom) and between Cases 2 and 4 (range-dependent layered bottom). For all frequencies, the standard deviation for the difference in TL between Cases 1 and $3\left(\sigma_{\Delta_{13}}\right)$ is greater than the standard deviation of the difference in TL between Cases 2 and $4\left(\sigma_{\Delta_{24}}\right)$. These results indicate including the range-dependent layered bottom decreases the effects of horizontal refraction/focusing. Examination of the gradient of the modal phase speed confirms this conclusion as Case 4 has a lower mean modal phase speed gradient than Case 3. An additional observation from Table II, is that the variance of TL is lowest for $50 \mathrm{~Hz}$, and appears to be saturated for higher frequencies.

\section{MEASUREMENTS OF HORIZONTAL REFRACTION}

The horizontal refraction/focusing effects described above are observed in the measured data from the SW06 experiment. Signals from the MSM and NRL sources are 

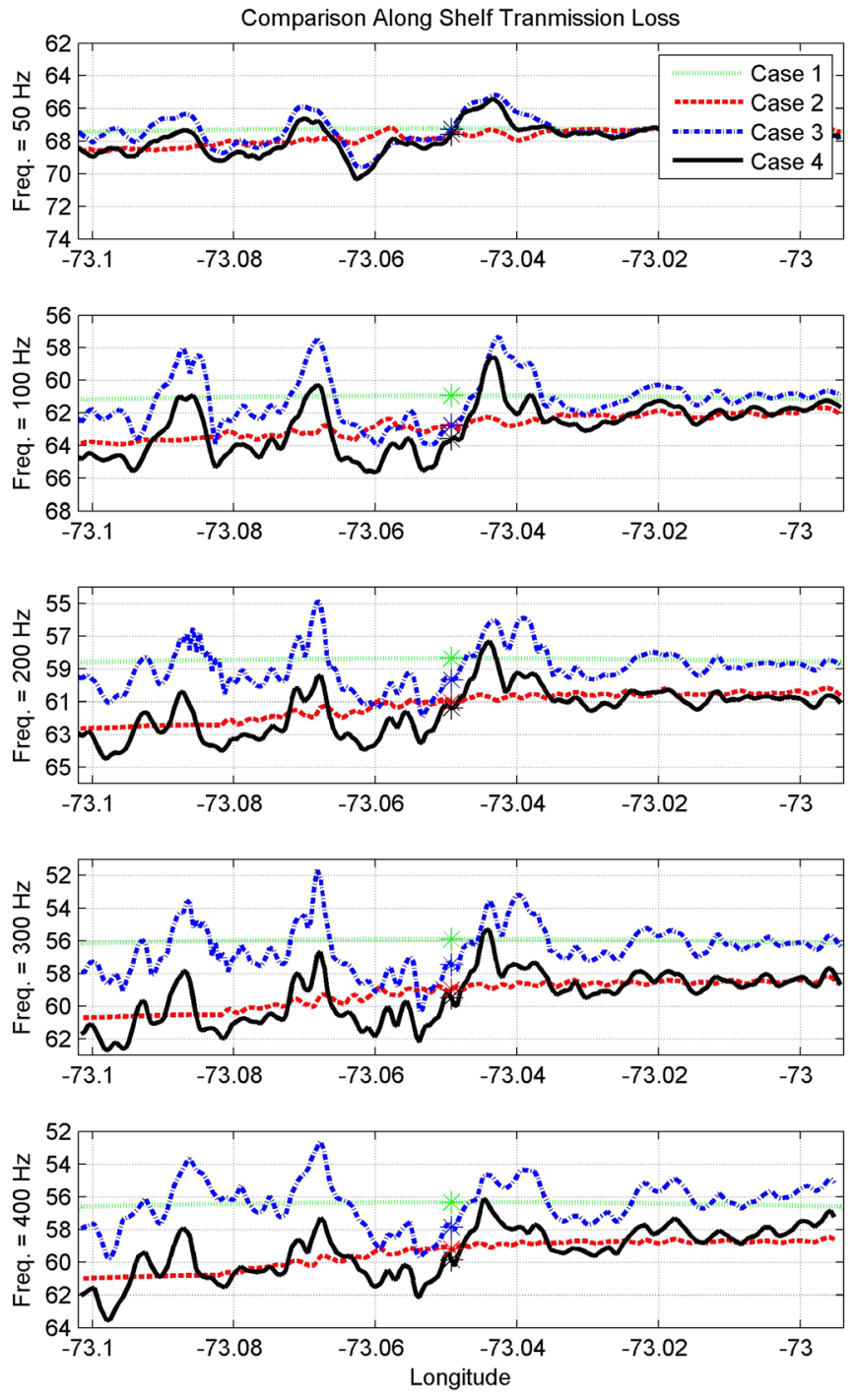

FIG. 9. (Color online) Comparison of TL across the shelf. The location of the receiver array is denoted by the stars.

compared, and different refraction effects are observed due to a relatively small separation of their locations. In the previous modeling section, propagation from the MSM source was considered, and detailed discussions on the horizontal refraction effects were given. In this section, the 3-D adiabatic normal mode model is also implemented for sound propagation from the NRL source, and the difference in the modeled sound field due to these two sources will be used to explain the observation and provide an evidence of sound focusing due to the seafloor scours.

During the SW06 experiment, the MSM source was moored at a depth of $56 \mathrm{~m}$ (the water depth in the surrounding

TABLE II. Standard deviation of the difference in across-shelf TL.

\begin{tabular}{lcc}
\hline \hline Frequency & $\sigma_{\Delta_{13}}$ & $\sigma_{\Delta_{24}}$ \\
\hline $50 \mathrm{~Hz}$ & $0.7987 \mathrm{~dB}$ & $0.7099 \mathrm{~dB}$ \\
$100 \mathrm{~Hz}$ & $1.4545 \mathrm{~dB}$ & $1.3087 \mathrm{~dB}$ \\
$200 \mathrm{~Hz}$ & $1.2647 \mathrm{~dB}$ & $1.0791 \mathrm{~dB}$ \\
$300 \mathrm{~Hz}$ & $1.4073 \mathrm{~dB}$ & $1.1684 \mathrm{~dB}$ \\
$400 \mathrm{~Hz}$ & $1.2911 \mathrm{~dB}$ & $1.0747 \mathrm{~dB}$ \\
\hline \hline
\end{tabular}

area is about $82 \mathrm{~m}$ ). This source transmitted continuous-wave tones at five frequencies (101.7253, 203.4505, 406.9010, 813.8021 and $1627.6042 \mathrm{~Hz}$ ) whose phases were separately encoded with different Maximum length sequences (Msequences). ${ }^{42}$ These phase-coded signals were transmitted sequentially (from low frequency to high frequency) every half hour for $7.5 \mathrm{~min}$, resulting in $1.5 \mathrm{~min}$ long transmission at each frequency. The signals of $101.7253 \mathrm{~Hz}$ and $203.4505 \mathrm{~Hz}$ are considered here (abbreviated to MSM100 and MSM200). As for the NRL source, it was located $686 \mathrm{~m}$ northeast of the MSM source and moored at a depth of $72 \mathrm{~m}$. This source transmitted $2.048 \mathrm{~s}$ long linear frequency modulated (LFM) chirps with a center frequency of $300 \mathrm{~Hz}$ and bandwidth of $60 \mathrm{~Hz}$. The transmitting period of these LFM chirps (abbreviated to NRL300) was also every half hour for $7.5 \mathrm{~min}$. In fact, the transmission schedules of the MSM and NRL sources coincided with each other. The receptions of MSM and NRL signals along the $468 \mathrm{~m}$ long Shark HLA, which was orientated to the north of the Shark VLA, are considered as they provide the longest available horizontal aperture.

Before presenting the measured data, a numerical model of 3-D sound propagation at a fixed frequency is shown to demonstrate variations of horizontal refraction/focusing solely due to changes of source positions. TL contours calculated from the incoherent mode sum for a frequency of $300 \mathrm{~Hz}$ from the MSM and NRL sources to the Shark HLA are shown in Fig. 10. The fully rangedependent environment (Case 4) is used. Both solutions result in horizontal focusing as shown in Figs. 10(a) and 10(c). However, differences in the horizontal refraction patterns can be observed. Furthermore, the close-up views near the Shark HLA, Figs. 10(b) and 10(d), show that the field from the NRL source position results in a focused beam passing over the center of the array, whereas the MSM beam just miss the array. Note that the specific topographic feature responsible for the focused beam near the array location has been identified using normal mode ray theory shown in Figs. 5 and 6.

Twenty-two days of data recorded on the Shark HLA were processed. It was necessary to consider a sufficiently long time period to distinguish the stationary effects of sound propagation caused by the bottom from the temporal variability of sound propagation due to water column fluctuations. In addition, the received signals are matched-filtered using the known phase modulations to increase signal-tonoise ratios, so to suppress the noise influence on signal intensity estimates. The compressed pulses resulting from matched filter processing are further band-pass filtered to allow narrowband comparisons with models. The bandwidth of the filter is $10 \mathrm{~Hz}$ centered at the center frequency of each signal. Examination of the filtered pulses shows that the pulse durations are about $0.8 \mathrm{~s}$ for MSM100 signals and $0.6 \mathrm{~s}$ for both MSM200 and NRL300 signals. The observed spreading of the pulses agrees with the normal mode dispersion calculated using the environmental model described above. The received levels (RL) of signals along the HLA are obtained from the root-mean-squares of the filtered pulses over the observed pulse durations. The distribution of the RL for each of the three signals over 22 days is plotted in 
(a) NRL Source

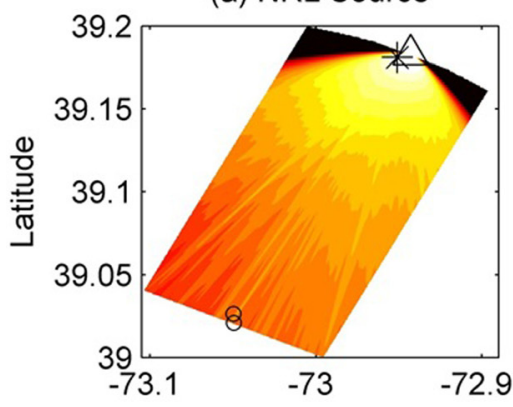

(c) MSM Source

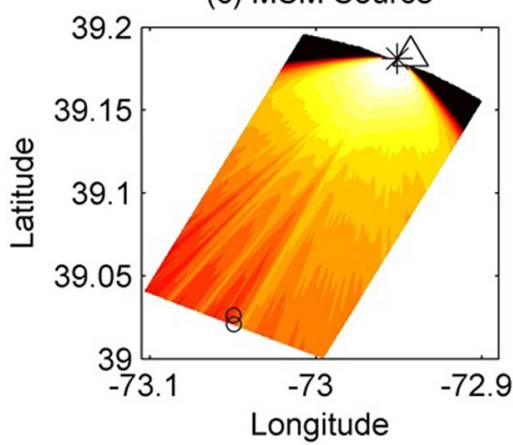

(b) NRL Source

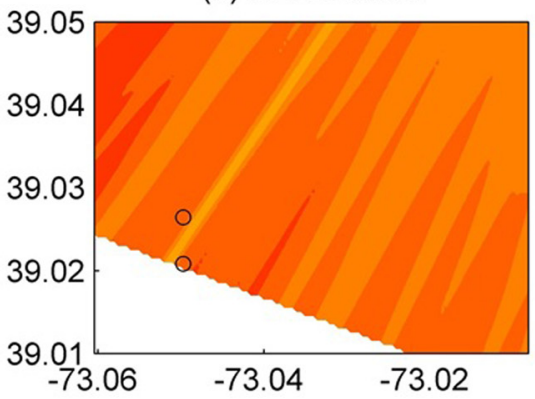

(d) MSM Source

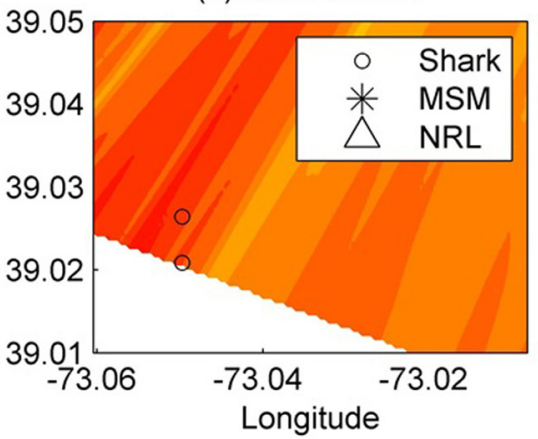

FIG. 10. (Color online) The modeled TL for the incoherent mode sum for a $300 \mathrm{~Hz}$ source at (a) and (b) the location of the NRL source and (c) and (d) the location of the MSM source. The plots on the left show propagation from the source to receiver, the plots on the right are a close up of TL at the HLA, whose two ends are denoted by circles.

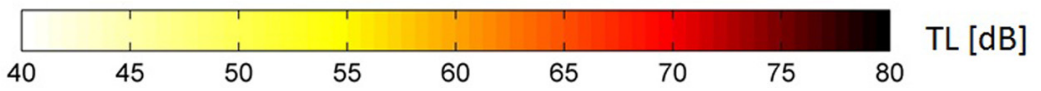

Figs. 11(a)-11(c). Overlaid on the each of the plots is the modeled RL calculated from the incoherent mode sum from each source. Use of the incoherent mode sum is appropriate for narrowband signals in long-range propagation when the modal arrivals at the receiver are separated in time (less inter-interference) and the dispersion of each individual mode over the narrow bandwidth is negligible, which are the cases in the processed Shark HLA data.

The RL distributions at some channels appear shifted compared to the neighboring channels; those channels were located at 78, 168, 288, 393 and $453 \mathrm{~m}$ along the HLA [see Fig. 11(a)-11(c)]. This was most likely caused by inconsistent (a) NRL300

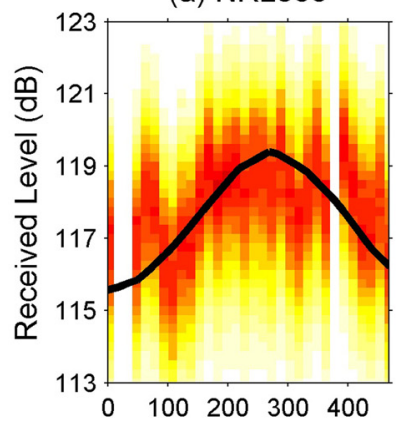

(d) NRL300 - MSM200

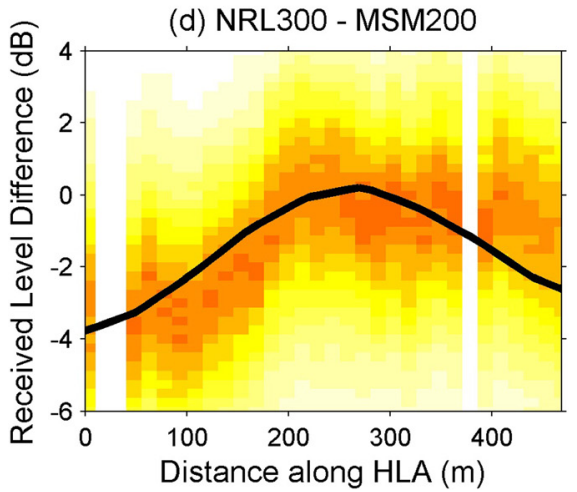

(b) MSM200

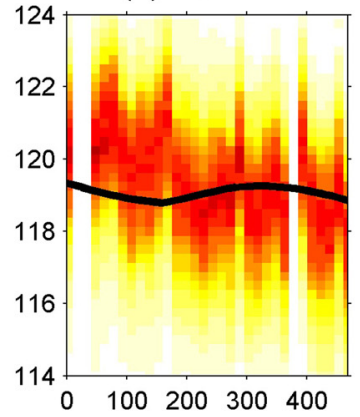

(c) MSM100

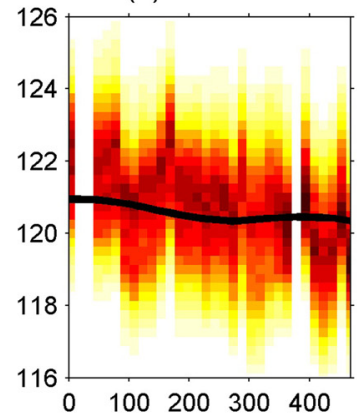

(e) NRL300 - MSM100

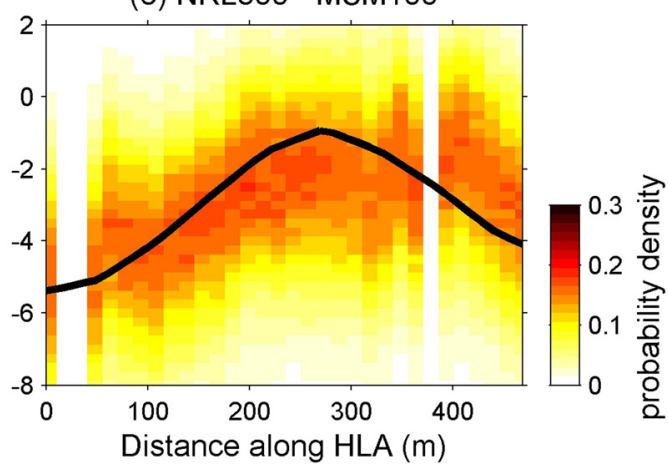

FIG. 11. (Color online) Distribution of measured RL from the (a) the NRL300 signal, (b) the MSM200 signal, (c) the MSM100 signal, and the RL difference between (d) NRL300 and MSM200, and (e) NRL300 and MSM100. Distance is referenced to the Shark VLA. The lines are from the 3-D adiabatic model. 
hydrophone sensitivity, but the discrepancy was small, $1.5 \mathrm{~dB}$, and consistent over the frequency band of interest. Also, since the exact source level (SL) from each source was not measured during the experiment, the modeled RL is fit to the measured distribution using least squares regression with a simple sonar equation, $\mathrm{RL}=\mathrm{SL}-\mathrm{TL}$. The following SL estimates are found to provide the best fit: $174.4 \mathrm{~dB}$ for NRL300, $180.8 \mathrm{~dB}$ for MSM200 and $185.0 \mathrm{~dB}$ for MSM100. Note that, as the constant attenuation and density profiles used in the model are not necessarily consistent with the true environment, these SL estimates are only approximations.

The measured and modeled RL agree well. The intensification along the HLA due to the horizontal focusing of the NRL300 signal is significant. The model showed that the focused beams of the MSM signals would miss the HLA (see Fig. 10), and this result is supported with the somewhat flat RL measurements along the array. Distributions of the RL difference of these three signals at each transmission period are shown in Figs. 11(d) and 11(e) along with the modeled curves. Both the measured and modeled RL differences

(a) Sensitivity to Source Location

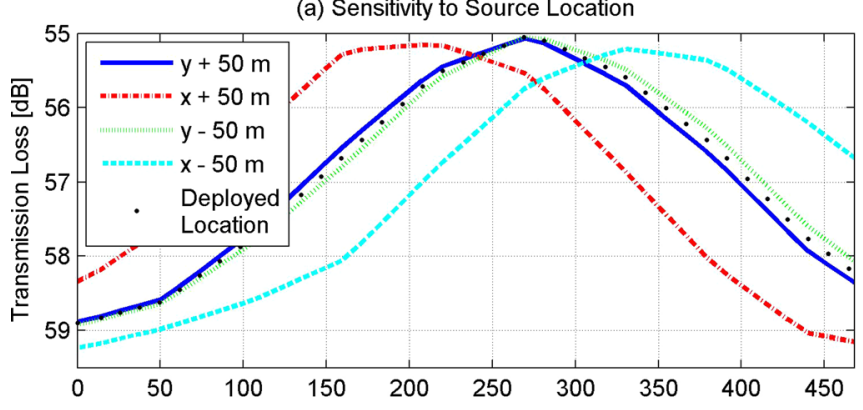

(b) Sensitivity to Environmental Sampling

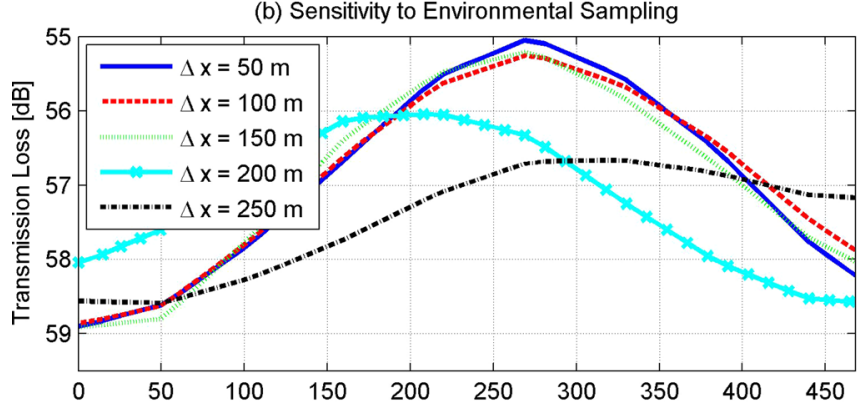

(c) Sensitivity to Mode Coupling

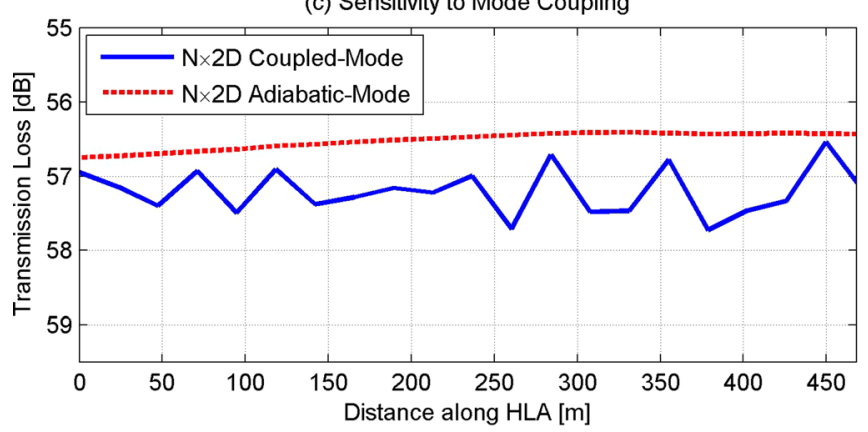

FIG. 12. (Color online) Sensitivity of modeled TL along the Shark HLA to (a) the location of the NRL source, (b) the discretization of the environmental data, and (c) the effects of mode-coupling. In all three plots, distance is referenced to the Shark VLA. show approximately $4 \mathrm{~dB}$ intensification near a position of $250 \mathrm{~m}$ north of the VLA. However, slight data-model disagreement is observed at the north end of the array for which the measured data indicate higher RL. This mismatch is possibly caused by uncertainties in the source locations and the environmental model which includes the sediment properties and seafloor topography. Discussions on the possible causes are provided below.

The uncertainty of the NRL source location is of particular interest as it affects the location of horizontal focusing along the HLA. Therefore, the sensitivity of modeled TL along the Shark HLA to location of the NRL source is examined. The acoustic field is calculated for source locations $\pm 50 \mathrm{~m}$ in the along- and across-shelf directions. The results of this study [Fig. 12(a)] show that TL is most sensitive to source's location across the shelf. Moving the source in the shoreward direction (x) for $50 \mathrm{~m}$ results in shifting of the intensification $75 \mathrm{~m}$ closer to the VLA. Similarly, placing the source $50 \mathrm{~m}$ further out to sea caused the focused beam to arrive approximately $75 \mathrm{~m}$ north of its unperturbed location. On the other hand, movement of the source along the shelf $(y \pm 50 \mathrm{~m})$ has only little effect on the location of horizontal focusing along the HLA. With this sensitivity study we can conclude that the slight mismatch seen in the data-model comparison (Fig. 11) should not be caused by source position errors, since the main lobe of the modeled RL intensification matches well with the data.

The second source of uncertainty in the modeled TL is associated with the environmental data. The effects subbottom structure and seafloor topography on TL were investigated in Sec. IV. The comparison of Cases 3 and 4 in Fig. 9 illustrates that amplitude and location of RL intensification caused horizontal focusing are affected by the rangedependent sediment properties. For this environment, it was also shown that 3-D effects are most sensitive to seafloor topography. Therefore, inaccuracies in the sub-bottom structure and/or seafloor topography data could be responsible observed differences in the measured and modeled RL.

Related to the accuracy of the environmental data is its resolution. The important length scale for medium heterogeneity corresponds to the width of the first Fresnel zone ${ }^{43}$ $R_{f}=\frac{1}{2}(\lambda R)^{1 / 2}$ where $R$ is the source-receiver separation and $\lambda=c / f$. For the NRL300 signal recorded on the HLA, $R_{f}=158 \mathrm{~m}$. The discretization of the measured data are well within this bound: $\Delta x=50 \mathrm{~m}$. The validity of the Fresnel zone criterion was ascertained by downsampling the measured bathymetry data to create coarser samplings of the environment. The modeled TL along the Shark HLA is shown in Fig. 12(b) for five discretizations of the environmental data. For the first three discretizations, $\Delta x<R_{f}$ and there is good agreement amongst the solutions. For the two most coarse samplings of the environmental data, $\Delta x>R_{f}$ and both the amplitude and the location of the intensification are affected. This study shows that the resolution of the measured bathymetry data is not a likely source of error in the modeled TL data.

The final source of mismatch between the measured and modeled data pertains to approximations made in the propagation model, particularly the assumption that the modes 
propagate adiabatically. To quantify this inaccuracy, the effect of mode coupling was assessed by applying an $\mathrm{N} \times 2 \mathrm{D}$ coupled-mode model. ${ }^{44}$ The incoherent mode sum for the $\mathrm{N} \times 2 \mathrm{D}$ coupled-mode solution is shown with the $\mathrm{N} \times 2 \mathrm{D}$ adiabatic-mode solution in Fig. 12(c). Comparison of these solutions shows that including mode coupling results in approximately $1 \mathrm{~dB}$ of higher loss. Additionally, the coupled-mode solution is characterized by fluctuations along the array on the order of $0.5 \mathrm{~dB}$ about the mean. This analysis shows the effects of mode-coupling (on the order of $1 \mathrm{~dB})$ are secondary to the effects of horizontal refraction (on the order of $4 \mathrm{~dB}$ ). Therefore, neglecting mode-coupling in the 3-D solution is not considered to be a significant source of model-data mismatch.

\section{CONCLUSIONS}

Three-dimensional propagation effects caused by seafloor scours and range-dependent layered bottom structure over a $20 \mathrm{~km}$ range along the New Jersey shelf were investigated. Examination of modal amplitudes in the propagation models demonstrated the effects of environmental range dependence on modes trapped in the water column, modes interacting with the seafloor, and modes trapped in the bottom. The model also suggests that horizontal refraction due to the presence of seafloor scours can cause TL deviation of up to $4 \mathrm{~dB}$, comparing to the baseline case of smoothed seafloor.

An intensification of sound recorded along a HLA of hydrophones during SW06 experiment was interpreted as horizontal focusing by comparing the measurements to modeled data. A modal ray trace was used to identify the topographic feature responsible for the observed focusing effect, which is a localized topographic depression near the sources. In addition, the models also found that although broad topographic features cause small gradients in modal phase speed, such features still have a considerable effect on TL because the affected rays continue to interact with the seafloor as they propagate across the shelf. Finally, even though the effects of the seafloor and sub-bottom structures are profound, they will be masked episodically by the presence of water column fluctuations, such as nonlinear internal waves.

\section{ACKNOWLEDGMENTS}

Work sponsored by the Office of Naval Research under Grants No. N00014-04-1-0146, No. N00014-10-1-0040, and No. N00014-10-1-0649.

\section{APPENDIX}

To assess the accuracy in the adiabatic approximation of the 3-D propagation model used in this paper, a comparison is made between coupled- and adiabatic-mode solutions using $\mathrm{N} \times 2 \mathrm{D}$ technique. The $\mathrm{N} \times 2 \mathrm{D}$ solutions are then compared with the 3-D adiabatic-mode solution. For this example, propagation is considered for a frequency of $300 \mathrm{~Hz}$ from the location of the NRL source at a depth of $50 \mathrm{~m}$, with receivers in the $x-y$ plane at a depth of $20 \mathrm{~m}$. The rangedependent bathymetry of the New Jersey shelf environment is used with the range-independent sub-bottom (i.e., Case 3 (a) Nx2D Coupled Mode

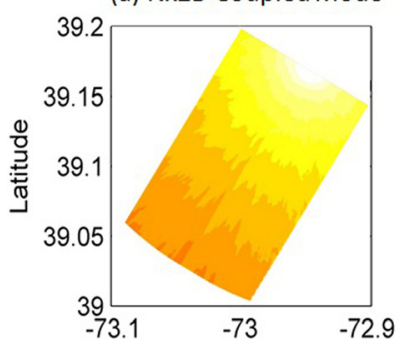

(c) 3D Adiabatic Mode

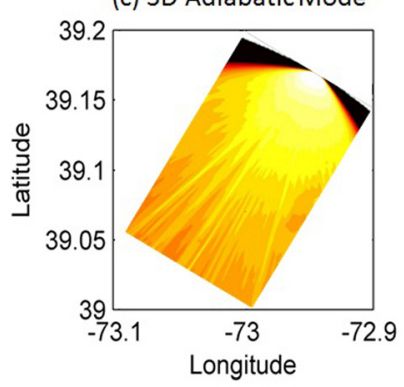

(b) Nx2D Adiabatic Mode

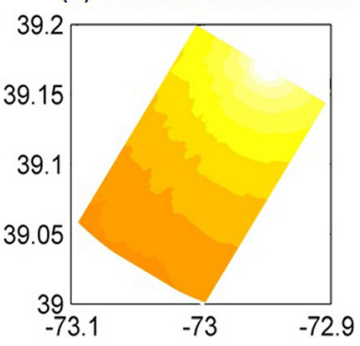

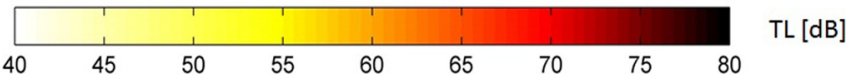

FIG. 13. (Color online) TL calculated from an incoherent mode sum using (a) $\mathrm{N} \times 2 \mathrm{D}$ coupled modes, (b) $\mathrm{N} \times 2 \mathrm{D}$ adiabatic modes, and (c) 3-D adiabatic modes.

from Sec. IV). The $\mathrm{N} \times 2 \mathrm{D}$ solutions were calculated using a coupled-mode model, ${ }^{44}$ with a false bottom inserted $40 \lambda$ below the seafloor. The solutions shown in Figs. 13(a) and 13(b) are calculated from an incoherent mode sum of 50 modes. The 3-D adiabatic-mode solution, calculated according to the modeling technique described in Sec. II, is shown for comparison in Fig. 13(c).

Although all three solutions show variability in the horizontal plane, the 3-D adiabatic-mode solution shows the strongest range-dependence. At a range of $20 \mathrm{~km}$ from the source, the oscillations in the field calculated by the 3-D model are an order of magnitude greater than those of the $\mathrm{N} \times 2 \mathrm{D}$ adiabatic-mode model. Clearly, a 3-D model is necessary to capture the fluctuations in the acoustic field. Comparison of the $\mathrm{N} \times 2 \mathrm{D}$ adiabatic- and coupled-mode solutions indicates that including mode coupling results in a solution with higher loss and greater variability. However, these effects are relatively small. At a range of $20 \mathrm{~km}$, on average, the $\mathrm{N} \times 2 \mathrm{D}$ solutions differ by $0.5 \mathrm{~dB}$. Therefore, the effects of mode-coupling are secondary to those of horizontal refraction.

${ }^{1}$ D. B. Reeder, L. Y. S. Chiu, and C. Chen, "Experimental evidence of horizontal refraction by nonlinear internal waves of elevation in shallow water in the south China Sea: $3 \mathrm{D}$ versus $\mathrm{N} \times 2 \mathrm{D}$ acoustic porpagation modeling," J. Comput. Acoust. 18, 267-278 (2010).

${ }^{2}$ J. F. Lynch, Y.-T. Lin, T. F. Duda, and A. E. Newhall, "Acoustic ducting, reflection, refraction, and dispersion by curved nonlinear internal waves in shallow water,” IEEE J. Oceanic Eng. 35, 12-27 (2010).

${ }^{3}$ M. Badiey, B. G. Katsnelson, Y.-T. Lin, and J. F. Lynch, "Acoustic multipath arrivals in the horizontal plane due to approaching nonlinear internal waves,” J. Acoust. Soc. Am. 129, EL141-EL147 (2011).

${ }^{4}$ R. Doolittle, A. Tolstoy, and M. J. Buckingham, "Experimental confirmation of horizontal refraction from a point source in a wedge-shaped ocean," J. Acoust. Soc. Am. 83, 2117-2125 (1988). 
${ }^{5}$ K. D. Heaney and J. J. Murray, "Measurement of three-dimensional propagation in a continental shelf environment," J. Acoust. Soc. Am. 125, 1394-1402 (2009).

${ }^{6}$ K. D. Heaney, W. A. Kuperman, and B. E. McDonald, "Perth-Burmuda sound propagation (1960): Adabatic mode intepretation," J. Acoust. Soc. Am. 90, 2586-2594 (1991).

${ }^{7}$ G. B. Deane, "The penetrable wedge as a three dimensional benchmark," J. Acoust. Soc. Am. 103, 2989 (1998).

${ }^{8}$ D. Tang, J. N. Moum, J. F. Lynch, P. Abbot, R. Chapman, P. H. Dahl, T. F. Duda, G. Gawarkiewicz, S. Glenn, J. A. Goff, H. Graber, J. Kemp, A. Maffei, J. D. Nash, and A. Newhall, "Shallow water' 06: A joint acoustic propagation/nonlinear internal wave physics experiment," Oceanography 20, 156-167 (2007).

${ }^{9}$ H. Weinberg and R. Burridge, "Horizontal ray theory for ocean acoustics," J. Acoust. Soc. Am. 55, 63-79 (1974).

${ }^{10}$ D. Lee, G. Botseas, and W. L. Siegmann, "Examination of threedimensional effects using a propagation model with azimuthal-coupling capability (for3d)," J. Acoust. Soc. Am. 91, 3192-3202 (1992).

${ }^{11}$ M. Collins, "The adiabatic mode parabolic equation," J. Acoust. Soc. Am. 94, 2269-2278 (1993).

${ }^{12}$ A. Tolstoy, "3-D propagation issues and models," J. Comput. Acoust. 4, 243-271 (1996).

${ }^{13}$ A. T. Abawi, W. A. Kuperman, and M. Collins, "The coupled mode parabolic equation,” J. Acoust. Soc. Am. 102, 233-238 (1997).

${ }^{14} \mathrm{~K}$. B. Smith, "A three dimensional propagation algorithm using finite azimuthal aperture," J. Acoust. Soc. Am. 106, 3231-3239 (1999).

${ }^{15}$ D. Lee, A. D. Pierce, and E. Shang, "Parabolic equation development in recent twentieth century," J. Comput. Acoust. 8, 527-637 (2000).

${ }^{16} \mathrm{~F}$. Sturm, "On the use of higher-order azimuthal schemes in 3-D PE modeling," J. Acoust. Soc. Am. 113, 3134-3145 (2003).

${ }^{17} \mathrm{~S}$. R. Rutherford, "An examination of coupled mode theory as applied to underwater sound propagation," Ph.D. thesis, University of Texas at Austin (1979).

${ }^{18}$ E. K. Westwood, C. T. Tindle, and N. R. Chapman, "A normal mode model for acousto-elastic ocean environments," J. Acoust. Soc. Am. 100, 3631-3645 (1996).

${ }^{19}$ J. A. Fawcett, "A derivation of the differential equations of coupled-mode propagation," J. Acoust. Soc. Am. 92, 290-295 (1992).

${ }^{20} \mathrm{M}$. Collins, "Generalization of the split-step Pade solution," J. Acoust. Soc. Am. 96, 382-385 (1994)

${ }^{21}$ P. Ratilal, Y. Lai, D. T. Symonds, L. A. Ruhlmann, J. R. Preston, E. K. Scheer, M. T. Garr, C. W. Holland, J. A. Goff, and N. C. Markris, "Long range acoustic imaging of the continental shelf environment: The Acoustic Clutter Reconnaissance Experiment 2001,” J. Acoust. Soc. Am. 117, 1977-1998 (2005).

${ }^{22}$ M. S. Ballard, K. M. Becker, and J. A. Goff, "Geoacoustic inversion for the New Jersey shelf: Three dimensional sediment model," IEEE J. Oceanic Eng. 35, 28-42 (2010).

${ }^{23}$ C. S. Fulthorpe and J. A. Austin, Jr., "Shallowly buried, enigmatic seismic stratigraphy on the New Jersey outer shelf: evidence for the latest Pleistocene catastrophic erosion?," Geology 32, 1013-1016 (2004).

${ }^{24}$ M. Santra, J. A. Goff, R. Steel, and J. A. Austin, Jr., "CHIRP seismic reflection study of falling-stage (forced regressive) sediment wedges on the New Jersey outer continental shelf," Eos Trans. AGU Fall Meet. Suppl. 88(2007), abstract OS53A-0983.

${ }^{25}$ S. P. S. Gulick, J. A. Goff, J. A. Austin, Jr., C. R. Alexander, S. Nordfjord, and C. S. Fulthorpe, "Basal inflection-controlled shelf-edge wedges off New Jersey track sea-level fall," Geology 33, 429-432 (2005).

${ }^{26}$ T. A. Davies, J. A. Austin, Jr., M. B. Lagoe, and J. D. Milliman, "Late Quaternary sedimentation off New Jersey: New results using 3-D seismic profiles and cores," Mar. Geol. 108, 323-343 (1992).
${ }^{27}$ J. F. Lynch, A. E. Newhall, B. J. Sperry, G. Gawarkiewicz, A. Fredricks, P. Tyack, C. S. Chui, and P. Abbot, "Spatial and temporal variations in acoustic propagation characteristics at the New England shelfbreak front," IEEE J. Oceanic Eng. 28, 129-150 (2003).

${ }^{28}$ B. J. Sperry, J. F. Lynch, G. Gawarkiewicz, C.-S. Chui, and A. E. Newhall, "Characteristics of acoustic propagation to the eastern vertical line array reciever during the summer 1996 New England shelfbreak PRIMER Experiment,” IEEE J. Oceanic Eng. 28, 729-749 (2003).

${ }^{29}$ M. S. Ballard and K. M. Becker, "Inversion for range-dependent water column sound speed profiles on the New Jersey shelf using a linearized perturbative method," J. Acoust. Soc. Am. 127, 3411-3421 (2011).

${ }^{30}$ M. Snellen, D. G. Simons, M. Siderius, J. Sellschopp, and P. L. Nielsen, "An evaluation of the accuracy of shallow water matched field inversion results," J. Acoust. Soc. Am. 109, 514-527 (2001).

${ }^{31}$ C. A. Linder and G. Gawarkiewicz, "A climatology of the shelf break front in the Middle Atlantic Bight," J. Geophys. Res. 103, 405-423 (1998)

${ }^{32}$ Y.-T. Lin, A. E. Newhall, T. F. Duda, P. Lermusiaux, and P. Haley, "Merging multiple-partial-depth data time series using objective empirical orthogonal function fitting," IEEE J. Ocean Eng. 35, 710-721 (2010).

${ }^{33}$ M. Badiey, B. G. Katsnelson, J. F. Lynch, S. Pereselkov, and W. L. Siegmann, "Measurement and modeling of three-dimensional sound intensity variations due to shallow-water internal waves," J. Acoust. Soc. Am. 117, 613-625 (2005).

${ }^{34}$ J. R. Apel, M. Badiey, C.-S. Chiu, S. Finette, R. Headrick, J. Kemp, J. F. Lynch, A. Newhall, M. H. Orr, B. H. Pasewark, D. Tielbuerger, A. Turgut, K. von der Heydt, and S. Wolf, "An overview of the 1995 SWARM shallow water internal wave acoustic scattering experiment," IEEE J. Ocean Eng. 22, 465-500 (1997).

${ }^{35}$ E. L. Shroyer, J. N. Moun, and J. D. Nash, "Nonlinear internal waves over New Jersey's continental shelf," J. Geophys. Res. 116, 1-16 (2011).

${ }^{36} \mathrm{~A}$. Shmelev, "Three-dimensional acoustic propagation through shallow water internal, surface gravity and bottom sediment waves," Ph.D. thesis, Mass. Inst. Technol. and the Woods Hole Oceanogr. Inst., Cambridge, MA (2011).

${ }^{37}$ M. S. Ballard and K. M. Becker, "Wave number tracking of mesoscale water column variability in shallow water," in Underwater Acoustic Measurements: Technologies and Results, 3rd International Conference and Exhibition (2009).

${ }^{38}$ I. Tolstoy, "Resonant frequencies and high modes in layered wave guides," J. Acoust. Soc. Am. 28, 1182-1192 (1956).

${ }^{39}$ R. J. Cederberg, W. M. Carey, and W. L. Siegmann, "Modal analysis of geoacoustic influences on shallow water propagation," IEEE J. Ocean Eng. 22, 237-244 (1997).

${ }^{40}$ W. M. Carey, J. Doutt, R. B. Evans, and L. M. Dillman, "Shallow-water sound transmission measurements on the New Jersey continental shelf," IEEE J. Ocean Eng. 20, 321-336 (1995).

${ }^{41}$ K. Ohta and G. V. Frisk, "Modal evolution and inversion for seabed geoacoustic properties in weakly range-dependent shallow water waveguides," IEEE J. Ocean Eng. 22, 501-521 (1997).

${ }^{42}$ A. Newhall, T. Duda, K. von der Heydt, J. Irish, J. Kemp, S. Lerner, S. Libertore, Y.-T. Lin, J. Lynch, A. Maffei, A. Morozov, A. Scmelev, C. Sellers, and W. Witzell, "Acoustic and oceanographic observations and configuration information for the WHOI moorings from the SW06 Experiment," Technical Report WHOI-2007-04, Woods Hole Oceanogr. Inst., Cambridge, MA (2007).

${ }^{43}$ C. S. Clay and H. Medwin, Acoustical Oceanography: Principles and Applications (Wiley, New York, 1977).

${ }^{44}$ R. B. Evans, "A coupled mode solution for acoustic propagation in a waveguide with stepwise depth variations of a penetrable bottom," J. Acoust. Soc. Am. 74, 188-195 (1983). 